\title{
Mu opioid receptor (OPRMI) as a predictor of treatment outcome in opiate-dependent individuals of Arab descent
}

This article was published in the following Dove Press journal:

Pharmacogenomics and Personalized Medicine

6 September 2012

Number of times this article has been viewed

\author{
Laith N AL-Eitan' \\ Saied A Jaradat ${ }^{2}$ \\ Steve YS Su ${ }^{3}$ \\ Guan K Tay' \\ Gary K Hulse 4,5 \\ 'Centre for Forensic Science, \\ ${ }^{2}$ Princess Haya Biotechnology Center, \\ Jordan University of Science and \\ Technology, Irbid, Jordan; ${ }^{3}$ School \\ of Mathematics and Statistics, \\ ${ }^{4}$ School of Psychiatry and Clinical \\ Neurosciences, ${ }^{5}$ Unit for Research \\ and Education in Alcohol and Drugs, \\ Queen Elizabeth II Medical Centre, \\ The University of Western Australia, \\ Crawley, WA, Australia
}

Correspondence: Laith N AL-Eitan Centre for Forensic Science, The University of Western Australia, 35 Stirling Highway, Crawley WA 6009, Australia

Tel + 6I 864887286

Fax + 6I 864887285

Email laith_aleitan@hotmail.com
Background: A number of research studies on the genetics of opiate dependence have focused on the $\mu$-opioid receptor $(O P R M 1)$, which is a primary target for opiates. This study aims to identify genetic polymorphisms within the OPRM1 gene involved in response to the biopsychosocial treatment in opiate-dependent individuals of Arab descent.

Methods: Unrelated Jordanian Nationals of Arab descent $(N=183)$ with opiate dependence were selected for this study. These individuals, all males, met the DSM-IV criteria for opiate dependence and were undergoing a voluntary 8-week treatment program at a Jordanian Drug Rehabilitation Centre. All individuals were genotyped for 22 single nucleotide polymorphisms (SNPs) within the OPRM1 gene using the Sequenom MassARRAY ${ }^{\circledR}$ system (iPLEX GOLD). Statistical analyses were carried out using the R package.

Results: Patients receiving biopsychosocial treatment showed that there was a significant difference in their OPRM1 SNPs' genotyping distribution between good, moderate, and poor responders to the treatment at two sites (rs6912029 [G-172T], and rs12205732 [G-1510A], $P<0.05$, Fisher's exact test).

Conclusion: This study is the first report of an association between the OPRM1 G-172T and G-1510A polymorphisms and treatment response for opiate dependence. Specifically, this study demonstrated that the OPRM1 GG-172 and GG-1510 genotypes were more frequent among patients who were nonresponders to the biopsychosocial treatment. However, further pharmacogenetic studies in a larger cohort of opiate-dependent patients of Arab descent are needed to confirm these findings and identify individuals with increased chance of relapse.

Keywords: OPRM1, association, opiates, dependence, treatment response, Arab

\section{Introduction}

Opiates are considered to be among the most addictive illicit drugs. ${ }^{1}$ Anthony et $\mathrm{al}^{2}$ reported that $23 \%$ of individuals who use opiates at least once in their lifetime become dependent, compared to $17 \%$ for cocaine and $13 \%$ for other illicit drugs. Opiate dependence has the highest propensity for causing physical harm to the user, and societal harm through damage to family and social circles. The economic costs of opiate dependence are also high and include the costs of health care, social care, and crime..$^{3-6}$

Currently, the three major maintenance pharmacotherapies for the treatment of opioid dependence are methadone, buprenorphine, and naltrexone. ${ }^{7}$ When combined with psychosocial services, these maintenance treatments are effective in reducing opiate use, dangerous behavior, and criminal activity, while improving the mental health of patients. ${ }^{6,7}$ However, the majority of opiate-dependent individuals remain out of treatment, and those who remain in treatment exhibit only $60 \%-70 \%$ 
success rates. ${ }^{6}$ Therefore, it remains an essential goal to further the understanding of the factors underlying poor treatment outcomes and assist in the development of more individualized, optimized, and ultimately more effective treatments for opiate drug dependence.

Pharmacogenetic studies have shown that both methadone and buprenorphine display a large interindividual variability in their pharmacokinetics and contribute to high interindividual variability in response to opiate-dependence treatment. ${ }^{7-9}$ Meta-analyses of many studies of naltrexone hydrochloride have also suggested that the effect size for response over placebo is in the small-to-moderate range. ${ }^{10-14}$ Several genetic studies have suggested that naltrexone does not have therapeutic effects in some alcohol-dependent individuals. ${ }^{14-17}$ Human laboratory studies have also reported that alcohol increases endogenous opioids usage more in patients with a family history of alcohol dependence. ${ }^{18}$ Apart from alcohol dependence, little attention has been devoted to the possible genetic factors affecting the treatment response to naltrexone in opiate drug dependence. However, demonstrations of the role of the brain's opioidergic system in mediating drug tolerance and dependence have identified it as a potential source of interindividual variability in the pharmacodynamics' response to opioids (eg, heroin, buprenorphine, and methadone) and opiate antagonists such as naltrexone. ${ }^{14-17}$

Research into the genetics of opiate dependence has focused on the opioidergic system, which is the primary target for opiates - in particular, heroin. ${ }^{7,19}$ Heroin is converted into morphine in vivo and activates the opioid receptors $(\mu, \delta$, $\kappa){ }^{7,20,21}$ This modulates several physiological processes such as pain, reward, nociception, immune, and gastric function, and stress and treatment responses. ${ }^{7,20,21}$ The opioid receptor $\mu 1$ (OPRM1) is thought to account for most of the opioidergic effects. ${ }^{20-22}$ OPRM1 is also the primary site of action of endogenous ligands such as $\beta$-endorphin and enkephalin ${ }^{23}$ and $\mu$-opioid receptor antagonists such as naltrexone, ${ }^{24}$ agonists such as methadone, ${ }^{25}$ or partial antagonists such as buprenorphine. ${ }^{20}$ Haile et $\mathrm{al}^{19}$ reported that opiates' physiological and subjective effects are associated with enhanced release of $\beta$-endorphin.

The OPRM1 gene (6q24-q25; Gene ID: 4988) encodes the $\mu$ opioid receptor, which is widely distributed in the brain. ${ }^{26-28}$ The OPRM1 receptor is a membrane of the G protein-coupled receptor family, ${ }^{23,29}$ and over 300 OPRM1 sequence variants have been identified to date. ${ }^{30,31}$ The A118G Single-nucleotide polymorphism (SNP) in exon 1 of the OPRM1 gene is the SNP most frequently found in the human population. ${ }^{32}$
This polymorphism encodes an Asn40Asp amino acid substitution that appears to be associated with changes in function. Bond et $\mathrm{al}^{33}$ reported that $\beta$-endorphin has a higher binding affinity (threefold) at the Asp40 mutated receptor than at the receptor encoded by Asn40. ${ }^{33,34}$ In addition, $\beta$-endorphin activates $G$ protein-coupled inwardly rectifying potassium channels (GIRKs) more in the presence of the Asp40 allele than the Asn40 allele. ${ }^{33,34}$ However, other studies have reported that the binding affinity or potency of $\beta$-endorphin for the variant receptor is not different from the normal receptor. ${ }^{23,33-35}$ A recent meta-analysis reported that the OPRM1 Asn40Asp does not appear to affect risk for drug dependence, ${ }^{36}$ but other studies report that it may influence response to opioid antagonist treatment for alcohol dependence using naltrexone. ${ }^{37}$

Various studies have provided varied and conflicting results for an association between opioid receptor gene polymorphism and treatment response. ${ }^{35-41}$ For example, Oslin et al found that individuals with the Asp40 allele had significantly lower rates of relapse and took longer to resume heavy drinking than Asn40/Asn40 homozygous in a sample of 130 European American alcoholics receiving naltrexone as treatment. ${ }^{42}$ A similar result has been found in Korean alcoholics with a higher therapeutic effect of naltrexone in individuals who had the Asp40 variant genotype compared to the Asn40 genotype. ${ }^{39}$

As very few pharmacogenetics studies have been conducted on the treatment of opiate dependence, such studies are required to better understand how opiate addicts respond to specific drug treatments. This study aimed to identify genetic variations within the OPRM1 gene involved in responsiveness to the biopsychosocial treatment in Jordanian opiate-dependent patients of Arab descent.

\section{Materials and methods Study patients}

Patients for this study were recruited from inpatient and outpatient programs at the National Centre for Rehabilitation of Addicts (NCRA) at the Jordanian Ministry of Health and the Drug Rehabilitation Centre at the Jordanian Public Security Directorate (DRC-PSD). Inclusion criteria were having a diagnosis of opiate dependence and being unrelated Jordanian Arab males and between 18 and 58 years of age. The Diagnostic and Statistical Manual of Mental Disorders, Fourth Edition (DSM-IV) was used to assess the medical and psychiatric status of patients. ${ }^{43}$ Psychiatric diagnosis was established using a structured baseline interview, which was based on the Addiction Severity Index (ASI) criteria. ${ }^{44}$ The clinical diagnoses and structured clinical interviews were conducted 
by independent psychiatric consultants. Patients were excluded if any of the following applied: axis-I comorbidity such as diagnosis of schizophrenia, major depression, bipolar I and II disorder, schizoaffective disorder, a serious medical illness, or those receiving psychotropic medications. Those patients with serious medical conditions such as neuroendocrine, metabolic, or cardiovascular diseases, neurodegenerative disorders, or epilepsy were also excluded. If patients used more than one substance, they were included only if their major drug dependence was an opiate. Initially, 500 patients were screened (see Figure 1). Based on the inclusion and exclusion criteria mentioned above, 350 patients were approached to participate in this study. Of these patients, 130 patients could not finish the treatment program for clinical reasons. Of the remaining

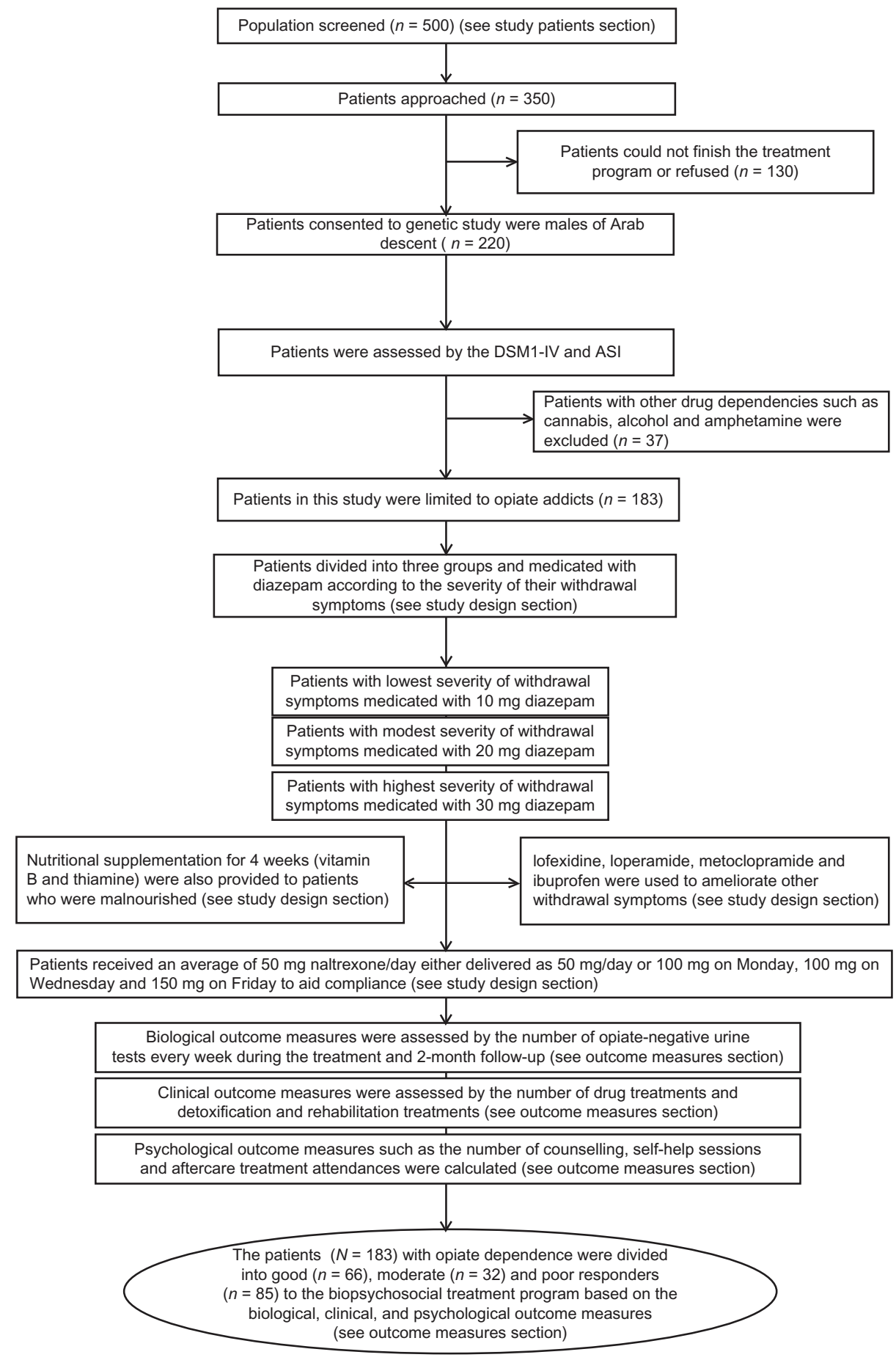

Figure I Flow chart of subjects, treatment approach, and outcome measures.

Abbreviations: ASI, The Addiction Severity Index; DSM-IV, The Diagnostic and Statistical Manual of Mental Disorders, Fourth Edition. 
patients, 220 agreed to be part of this study. A further $37(16 \%)$ patients were then excluded from the final analysis due to the type of drug dependence and the samples were limited to only opiate dependence. In total, complete data were obtained from 183 patients with opiate dependence.

This study was conducted according to the provisions of the Australian Medical Association Code of Ethics and the World Medical Association Declaration of Helsinki. The study was also subject to, and in compliance with, the National Statement on Ethical Conduct in Human Research, Australia (2007). Ethical approval to conduct this research was granted by the Human Research Ethics Committee of The University of Western Australia (Ref No RA/4/1/4344). This study was also approved by the Human Ethics Committee of the Jordanian Ministry of Health (Ref No Development/Trainees/535) and by the Institutional Review Board of the Jordan University of Science and Technology (Ref No RA/16/1/2010). Written informed consent was obtained from all patients before participation in the study.

\section{Study design}

At the initial screening, several procedures were undertaken to collect demographic and clinical data. These included capturing demographic data such as date of birth, sex, nationality, marital status, children, and occupation. A medical history including drug overdose and suicide attempts was also taken from the participants' medical records. Information on substance abuse was also collected from their medical records including type of substance, cause of addiction, initial date of addiction, starting and last taken amount of opiate, route of administration, withdrawal periods, and hospitalizations due to opiate abuse. Data on smoking status and blood relatives with a history of drug abuse were also collected from participarts' medical records. All data were coded and no specific individual was identified.

\section{Treatment approach}

All subjects who met the DSM-IV criteria for opiate dependence received biopsychosocial treatment in the NCRA and DRC-PSD programs (see Figure 1). Treatment consisted of 7-day inpatient detoxification using a regime of diazepam medication and 7-week oral naltrexone as maintenance treatment. This is often accompanied by withdrawal symptoms and occasionally fatal side effects. ${ }^{7}$ Four other oral medications (lofexidine, loperamide, metoclopramide, and ibuprofen) were used to ameliorate other withdrawal symptoms such as stomach cramps and diarrhea, and nutritional supplementations (vitamin B and thiamine) were provided for 4 weeks. The NCRA and DRC-PSD treatment program also provided patients with psychosocial support. Inpatient groups were offered counseling sessions three times a week for a total of 8 weeks. Each session lasted for 2 hours. In addition, patients participated in 1-hour individual counseling sessions per week over the 8-week treatment program. These participants were described as patients completing treatment and continuing with aftercare programs.

In the NCRA and DRC-PSD programs, chlordiazepoxide is prescribed for outpatients as it has a lower abuse potential. Valium (diazepam) is used for inpatients as it has a faster action and a higher dose effect. All patients are given four doses of diazepam every day at early morning, midday, early evening, and at bedtime and reviewed daily to assess withdrawal symptoms. On admission, they are given four separate doses of $30 \mathrm{mg}$. The next day's planned dosages are based on ongoing assessment of the patients' symptoms rather than the length of the course or the prescribed starting dose. The patients recruited for the study were divided into three groups according to the severity of their withdrawal symptoms. The first group of patients (lower-dose responders) had the lowest severity of withdrawal symptoms and were medicated with $10 \mathrm{mg}$ diazepam four times a day. The second group of patients (high-dose responders) had moderately severe withdrawal symptoms and were medicated with equal to or greater than $20 \mathrm{mg}$ diazepam four times a day. The third group of patients (high-dose nonresponders) consisted of nonresponders to treatment with severe withdrawal symptoms and were medicated with equal to or greater than $30 \mathrm{mg}$ diazepam four times a day. Four other oral medications were used to ameliorate other withdrawal symptoms: lofexidine, loperamide, metoclopramide, and ibuprofen. Lofexidine, an $\alpha$-adrenergic agonist, was used to reduce the other withdrawal symptoms such as chills, sweating, stomach cramps, diarrhea, muscle pain, runny nose, and watering eyes. These patients, underwent, a 10-day course of lofexidine treatment starting at $0.2 \mathrm{mg}$ two to four times a day and increasing in units of $0.4 \mathrm{mg}$ to a maximum of $2.4 \mathrm{mg}$. Loperamide was used for treatment of diarrhea. All patients were given an initial dose of $4 \mathrm{mg}$ after each loose stool up to a total of $16 \mathrm{mg}$ per day. Metoclopramide was used for the treatment of nausea and vomiting. Patients were prescribed $10 \mathrm{mg} /$ day up to a maximum of $30 \mathrm{mg} /$ day. Ibuprofen was used to reduce fever and headaches and treat muscle pains. Patients were given an initial dose of $0.4 \mathrm{mg}$ of ibuprofen every 4 to 6 hours, which was increased to a maximum daily dose of $1.6 \mathrm{mg}$ according to their response and tolerance to the drug. Supplementary vitamins (eg, vitamin B and thiamine) were also provided to patients who were malnourished. 
For the patients who had successfully completed the detoxification and withdrawal period and who had been opiate free for more than 7 days, the opiate antagonist, naltrexone, was used as an aid to prevent relapse and promote abstinence. The drug was given at a starting dose of $25 \mathrm{mg} /$ day, increased to $50 \mathrm{mg} /$ day. Sometimes, patients received an average of $50 \mathrm{mg}$ naltrexone/day either delivered as $50 \mathrm{mg} /$ day or $100 \mathrm{mg}$ on Monday, $100 \mathrm{mg}$ on Wednesday, and $150 \mathrm{mg}$ on Friday to aid compliance.

Patients completing the intensive program are offered an aftercare program, which includes one individual counseling session per week for up to 6 months. The treatment approach is problem-oriented and focuses on achieving well-defined goals such as the availability, accessibility, affordability, and efficiency to all substance abuse patients in need of treatment. These objectives are outlined in a treatment plan that is prepared at admission and is updated for each new treatment program. Medical, behavioral, supportive, and relapse prevention strategies are drawn from different treatment models. ${ }^{7}$ In this study, the treatment team was kept blind to the genetic status of the patients.

\section{Outcomes measures}

A semi-structured baseline interview was developed from the ASI criteria. These interviews were used to collect the demographic and clinical data of the 183 patients. The family history of substance abuse was also obtained. This allowed the subset of drug-dependent patients whose addiction may be influenced by genetic factors to be identified. ${ }^{45}$ Berrettini and Persico suggest that the likelihood of detecting susceptibility genes is higher in these individuals. ${ }^{46}$ In-treatment, end-oftreatment, and follow-up assessments were also conducted to provide valid estimates of opiate abstinence. Retention and attrition from treatment were also recorded (see Figure 1).

The measures to assess outcome were the number of negative urines. Urine drug screening (UDS) was performed for all patients at the NCRA and DRC-PSD on the day of admission to the treatment program. Every week during the treatment, after treatment completion and each follow up, the patients were randomly screened for drugs using The Multi Drug Test 10 Panel (Jant Pharmacal Corporation, Encino, CA). This test is a one-step immunoassay for the detection of cannabis, cocaine, phencyclidine, opiates, methamphetamine, methadone, amphetamine, barbiturates, benzodiazepines, and oxycodeine. The number of negative UDS for opiates was adopted as a measure of opiate abuse during and after treatment. Missed urine samples were not taken into account for data analysis.
The number of drug treatments and detoxification and rehabilitation treatments were recorded as this offered another estimate of treatment retention. Attendance was determined as duration from the date of admission to date of the last visit. The number of treatment sessions attended by the patients including the total number of counseling and self-help sessions was calculated. This measure was used to reflect participation in the treatment process. The number of patients who dropped out of treatment was also considered. Attrition was defined as patients who stopped attending the treatment program within 7 days of admission. Attendance at aftercare treatment was also recorded. The opiate-dependent patients $(n=183)$ were divided into good $(n=66)$, moderate $(n=32)$, and poor $(n=85)$ responders to the biopsychosocial treatment based on the biological, clinical, and psychological outcome measures mentioned above.

\section{SNP selection and genotyping}

To date, ten human OPRMI splice variants have been identified. They contain the same exons 1, 2, and 3 of the normal human OPRM1 (Gene ID: 4988, Gene bank Accession \#: NM_000914.2, Gene Alias: KIAA0403, MOR, MOR1, OPRM), which has four exons. However, they differ in their splicing downstream of exon 3. All splice variants result in amino acid sequence changes to the $\mathrm{C}$-terminus of the $\mu$-opioid receptor and may affect the activity of the receptor. ${ }^{47-49}$ Of these, the normal human OPRM1 gene has been most extensively investigated (Table 1). In this study, 22 OPRM1 SNPs were selected from public databases including the following: the SNP database of the National Centre for Biotechnology Information (NCBI) (http://www.ncbi. nlm.nih.gov/SNP/), the Applied Biosystems SNP database (http://www.appliedbiosystems.com), and the International HapMap Project (http://www.hapmap.org/). The positions of the SNPs in OPRMI and the relative distance to the translation initiation site are given in Table 1.

Genomic DNA was extracted from whole blood using a Gentra Puregene Kit (QIAGEN Inc, Valencia, CA). All individuals were genotyped for the chosen 22 SNPs within the OPRM1 gene using the Sequenom MassARRAY ${ }^{\circledR}$ system (iPLEX GOLD) (Sequenom, San Diego, CA). Briefly, PCR and single-base extension primers (SBE) were designed using MassARRAY assay design software (3.1; Sequenom), which allows iPLEX reactions for SBE designs with the modified masses associated with the termination mix. The manufacturer's instructions for the multiplex reaction were followed throughout the entire process, including the 
Table I List of SNPs within the OPRMI gene, their positions, and genotyping data based on the whole cohort $(N=183)$

\begin{tabular}{|c|c|c|c|c|c|}
\hline SNP_ID & Chr position ${ }^{a}$ & SNP & SNP gene location & Discrepancy rate $^{b}$ & Call rate ${ }^{c}$ \\
\hline rs6912029 & $|54,402,20|$ & $G>T$ & Upstream (5'-UTR) & $0.00 \%$ & $100 \%$ \\
\hline rs 12205732 & $154,400,626$ & $A>G$ & Upstream (5'-UTR) & $0.00 \%$ & $100 \%$ \\
\hline rs I79997| & $154,402,490$ & $A>G$ & Exon 1 & $0.00 \%$ & $100 \%$ \\
\hline rs510769 & $|54,403,7| 2$ & $A>G$ & Intron I & $0.00 \%$ & $100 \%$ \\
\hline rs5II435 & $154,410,240$ & $A>G$ & Intron I & $0.00 \%$ & $100 \%$ \\
\hline rs52473I & $154,416,785$ & $C>A$ & Intron I & $0.05 \%$ & $99 \%$ \\
\hline rs3823010 & $154,420,845$ & $A>G$ & Intron I & $0.00 \%$ & $100 \%$ \\
\hline rsI381376 & $|54,434,95|$ & $A>G$ & Intron I & $0.00 \%$ & $100 \%$ \\
\hline rs3778I5I & $154,435,373$ & $\mathrm{C}>\mathrm{T}$ & Intron I & $0.00 \%$ & $100 \%$ \\
\hline rs563649 & $154,449,660$ & $A>G$ & Exon 2 & $0.00 \%$ & $100 \%$ \\
\hline rs2075572 & $154,453,697$ & $C>G$ & Intron 2 & $0.00 \%$ & $100 \%$ \\
\hline rs540825 & $154,456,139$ & $\mathrm{~T}>\mathrm{A}$ & Intron 3 & $0.07 \%$ & $99 \%$ \\
\hline rs675026 & $154,456,256$ & $\mathrm{G}>\mathrm{A}$ & Intron 3 & $0.12 \%$ & $99 \%$ \\
\hline rs562859 & $154,456,266$ & $A>G$ & Intron 3 & $0.25 \%$ & $99 \%$ \\
\hline rs548646 & $154,459,840$ & $\mathrm{~A}>\mathrm{C} / \mathrm{G}>\mathrm{T}$ & Intron 3 & $0.52 \%$ & $97 \%$ \\
\hline rs648007 & $154,464,304$ & $\mathrm{C}>\mathrm{T}$ & Intron 3 & $0.00 \%$ & $100 \%$ \\
\hline rs9322447 & $154,466,013$ & $\mathrm{G}>\mathrm{A}$ & Intron 3 & $0.00 \%$ & $100 \%$ \\
\hline rs609|48 & I54,472,707 & $\mathrm{C}>\mathrm{T}$ & Intron 3 & $0.07 \%$ & $99 \%$ \\
\hline rs $606 \mid 48$ & I54,477,679 & $G>T$ & Intron 3 & $0.00 \%$ & $100 \%$ \\
\hline rs632395 & $154,478,944$ & $\mathrm{C}>\mathrm{T}$ & Intron 3 & $0.00 \%$ & $100 \%$ \\
\hline rs648893 & $|54,480,32|$ & $\mathrm{C}>\mathrm{T}$ & Intron 3 & $0.07 \%$ & $99 \%$ \\
\hline rs67|53I & $154,482,434$ & $A>G$ & Downstream (3'-UTR) & $0.00 \%$ & $100 \%$ \\
\hline
\end{tabular}

Notes: ${ }^{a}$ Chromosome positions are based on NCBI Human Genome Assembly Build 36.3; ${ }^{b}$ ratio of the number of discordant genotypes to the number of duplicates; ${ }^{\mathrm{C}}$ ratio of the number of valid genotypes to the number of subjects genotyped $(N=183)$ at each locus.

Abbreviations: 3'-UTR, 3' untranslated region; 5'-UTR, 5' untranslated region.

polymerase chain reaction (PCR) amplification (Sequenom), the shrimp alkaline phosphatase (SAP) enzyme (Sequenom) treatment to dephosphorylate the dNTPs unincorporated in the PCR, the SBE reactions using an iPLEX GOLD assay (Sequenom), and the clean-up with a resin kit (Sequenom) to desalt the iPLEX reaction products. PCR and SBE primer sequences and all protocol conditions are available upon request. Reaction products were dispensed onto a 384-element SpectroCHIP bioarray (Sequenom) using a MassARRAY Nanodispenser and assayed on the MassARRAY platform. Mass differences were detected with matrix-assisted laser desorption/ionization time-offlight mass spectrometry (MALDI-TOF MS). MassARRAY Workstation software (v.3.3; Sequenom) was used to process and analyze the iPLEX SpectroCHIP bioarray. Typer Analyzer v.4.0.2 software (Sequenom) was used to analyze all genotypes obtained from the assays.

\section{Statistical analysis}

Consistency with Hardy-Weinberg equilibrium (HWE) was tested using an exact test implemented in PowerMarker software (version 3.25; Paul Lewis, Bioinformatics, North Carolina State University: see http://statgen.ncsu.edu/powermarker). ${ }^{50}$ Continuous variables were compared using the ANOVA
$F$-test, Kruskal-Wallis test, Wilcoxon rank-sum test, Welch test, and Student's $t$-test as appropriate. Categorical variables were analyzed using Pearson's $\chi^{2}$ tests, and Fisher's exact test. A significance level of $\alpha=0.05$ was applied and a variance of $P<0.05$ was considered to be statistically significant. All statistical analyzes were carried out using R software (http:// www.r-project.org/).

\section{Results}

\section{Sample characteristic}

The study group consisted of 183 unrelated Jordanian Arab males meeting the DSM-IV criteria ${ }^{43}$ for opiate dependence. The majority of these patients $(92 \%)$ also had nicotine codependence. Cannabis abuse was common (58\%) and 53\% were alcoholics. The mean age $( \pm \mathrm{SD})$ of these patients was $33 \pm$ (8.6) years with a range of 18 to 58 years. The median age of the patients was 32 (range: 18 to 58). Both genotype and phenotype data were available for these patients.

All patients received biopsychosocial treatment at the NCRA and the DRC-PSD for 8 weeks. There were 66 (36\%) good responders, 32 (18\%) moderate responders, and 85 (46\%) poor responders. The description of the three groups, including demographic, nicotine status, opiate consumption (beginning and last taken amount [grams per day]), drug use, dependence 
Table 2 Details of the 183 opiate-dependent patients classified into three groups

\begin{tabular}{|c|c|c|c|c|c|}
\hline Category & Subcategory & Good responders & Moderate responders & Poor responders & $P$ value ${ }^{f}$ \\
\hline \multirow[t]{7}{*}{ Demographics } & Patients (n, \%) & $(66 / 183) 36 \%$ & (32/183) $18 \%$ & $(85 / 183) 46 \%$ & \\
\hline & Age $^{\mathrm{a}}$ [years] & $31.0[7.64]$ & $33.1[9.64]$ & $34.5[8.68]$ & 0.04698 \\
\hline & Marital (single, married, divorced) (\%) & $(47 \%, 53 \%, 0 \%)$ & $(47 \%, 50 \%, 3 \%)$ & $(24 \%, 72 \%, 5 \%)$ & $0.0055^{\mathrm{h}}$ \\
\hline & Education (\%) & $26 \%$ & $16 \%$ & $20 \%$ & $0.4770^{i}$ \\
\hline & Employment (\%) & $33 \%$ & $31 \%$ & $44 \%$ & 0.3120 \\
\hline & Children (\%) & $41 \%$ & $44 \%$ & $75 \%$ & $<0.000 \mathrm{I}^{\mathrm{i}}$ \\
\hline & Family with history of drug use (\%) & $21 \%$ & $31 \%$ & $20 \%$ & $0.4110^{i}$ \\
\hline \multirow[t]{3}{*}{ Nicotine status } & Nicotine (\%) & $80 \%$ & $94 \%$ & $82 \%$ & $0.1830^{i}$ \\
\hline & $\mathrm{Age}^{\mathrm{a}}$ when start smoking [years] & |3.1 [7.33] & I4.6 [5.00] & $12.9[6.99]$ & $0.4880^{g}$ \\
\hline & Nicotine cigarette per day $(\#)$ & $23.9[18.30]$ & $34.8[16.70]$ & $29.6[21.80]$ & $0.0304^{8}$ \\
\hline \multirow[t]{2}{*}{ Opiate consumption } & Beginning taken amount ${ }^{\mathrm{a}}$ (grams per day) & $0.495[0.27]$ & $0.362[0.215]$ & $0.864[2.67]$ & $0.3030^{\mathrm{g}}$ \\
\hline & Last taken amount ${ }^{\mathrm{a}}$ (grams per day) & $0.996[0.67]$ & $0.86[0.52]$ & $\mathrm{I} .43[0.81]$ & $<0.000 I^{g}$ \\
\hline \multirow[t]{5}{*}{ Other drug use ${ }^{b}$} & Alcohol (\%) & $61 \%$ & $53 \%$ & $67 \%$ & $0.3590^{i}$ \\
\hline & Cocaine (\%) & $3 \%$ & $3 \%$ & $2 \%$ & $1.0000^{\mathrm{h}}$ \\
\hline & Benzodiazepines (\%) & $55 \%$ & $31 \%$ & $68 \%$ & $0.0014^{i}$ \\
\hline & Amphetamine (\%) & $14 \%$ & $28 \%$ & $8 \%$ & $0.0203^{i}$ \\
\hline & Cannabis (\%) & $56 \%$ & $31 \%$ & $60 \%$ & $0.0184^{i}$ \\
\hline \multirow[t]{3}{*}{ Opiate dependence } & Age $e^{a}$ first opiate use (years) & $22.1[6.5 I]$ & $22.8[7.08]$ & $22.3[6.08]$ & $0.8850^{\mathrm{g}}$ \\
\hline & Age $^{\mathrm{a}}$ of onset (years) & $24.6[6.68]$ & $24.7[7.64]$ & $23.8[6.76]$ & $0.7150^{\mathrm{g}}$ \\
\hline & Duration of opiate use $\mathrm{a}^{\mathrm{a}}$ (years) & $6.02[3.48]$ & $7.62[4.96]$ & $11.9[6.9]$ & $<0.000 \mathrm{II}^{\mathrm{i}}$ \\
\hline Drug screening & Positive admit UDSc (\%) & $0 \%$ & $0 \%$ & $98 \%$ & $<0.000 \mathrm{I}^{\mathrm{i}}$ \\
\hline \multirow[t]{2}{*}{ Medical history ${ }^{d}$} & Overdose (\%) & $34 \%$ & $44 \%$ & $53 \%$ & $0.0657^{i}$ \\
\hline & Hepatitis (C virus infectious) & $5 \%$ & $6 \%$ & $2 \%$ & $0.5750^{i}$ \\
\hline \multirow[t]{6}{*}{ Psychiatric status $^{d}$} & Impulsive (\%) & $91 \%$ & $84 \%$ & $98 \%$ & $0.0330^{i}$ \\
\hline & Suicide attempts (\%) & $33 \%$ & $41 \%$ & $54 \%$ & $0.0349 i$ \\
\hline & Depression (\%) & $3 \%$ & $38 \%$ & $16 \%$ & $<0.000 \mathrm{I}^{\mathrm{i}}$ \\
\hline & Anxiety (\%) & $98 \%$ & $100 \%$ & $100 \%$ & $0.5360^{\mathrm{h}}$ \\
\hline & Craving (\%) & $35 \%$ & $62 \%$ & $71 \%$ & $<0.000 \mathrm{I}^{\mathrm{i}}$ \\
\hline & Euphoria (\%) & $50 \%$ & $38 \%$ & $78 \%$ & $<0.000 \mathrm{I}^{\mathrm{i}}$ \\
\hline \multirow[t]{5}{*}{ Hospitalization ${ }^{8}$} & Number ${ }^{a}$ of drug treatments & $2.6[1.87]$ & $2.3[1.42]$ & $2.5[1.78]$ & $0.6630^{\mathrm{g}}$ \\
\hline & Number ${ }^{a}$ of detoxification treatments & $2.6[1.89]$ & $2.3[1.44]$ & $2.5[1.78]$ & $0.6660^{g}$ \\
\hline & Number ${ }^{a}$ of rehabilitation treatments & $2.9[2.02]$ & $2.5[1.46]$ & $2.8[1.97]$ & $0.6250^{\mathrm{g}}$ \\
\hline & Number ${ }^{\mathrm{a}}$ of counseling sessions & $14.3[11.00]$ & $12.0[11.10]$ & $13.5[10.90]$ & $0.6290^{g}$ \\
\hline & Number ${ }^{\mathrm{a}}$ of self-help groups & $14.3[11.00]$ & $11.4[11.00]$ & $13.4[11.10]$ & $0.4810^{g}$ \\
\hline
\end{tabular}

Notes: a Standard deviation in square brackets; ${ }^{b}$ regardless whether prescribed or not as determined by substance screening tests at treatment entry; ${ }^{c}$ UDS: Urine Drug Screens at follow-up treatment; das obtained from their medical records at baseline; eaccumulative months of hospitalization treatment for psychiatric morbidity; fstatistically significant if $P<0.05$; the bold-faced $P$-values are those that are significant; ${ }^{\circ}$ ANOVA $f$-test; ' $F$ isher exact test; 'Pearson's Chi-squared test. ${ }^{~} K r$ ruskal-Wallis test.

variables, substance screening, drug toxicity, psychiatric status, and hospitalization treatment is given in Table 2.

\section{Association of SNP OPRMI genotypes with opiate-dependence variables and treatment response}

Genotypes determined by Sequenom MassARRAY ${ }^{\circledR}$ system for the 22 OPRM1 SNPs were highly accurate with an average success rate of $99.6 \%$. The average genotype discrepancy rate across the 22 loci was only $0.05 \%( \pm 0.12 \%)$ in the samples.

For the 183 opiate-dependent patients, no deviations from HWE were observed for the allele and genotype frequencies for the $22 \mathrm{SNPs}(P>0.5)$. When comparing the three inclusion groups (good, moderate, and poor responders), significant differences in proportions among genotypes were observed at two sites of the OPRM1 gene with response to the biopsychosocial treatment (rs6912029 [G-172T], $P=0.0329$ and rs12205732 [G-1510A], $P=0.0333$ ) (Table 4). Specifically, the GG-172 and GG-1510 carriers were more frequent in nonresponders to treatment. For example, the GG-172 carriers were $48 \%$ of the nonresponders group $(n=88)$, whereas they were $18 \%$ of the moderate responders group $(n=35)$ and were $34 \%$ of the responders group $(n=70)$.

There were also significant differences in the proportion of opiate use at treatment admission at six sites of the OPRM1 gene (rs2075572 [C644-83G], $P=0.011$, and rs648893 [C1165-1189T], $P=0.014$, rs609148 [G1165-8803T], $P=0.028$, rs 9322447 [G1164+11714A], $P=0.038$, rs671531 [A1164+28135A G], $P=0.032$, rs540825 [T1164+1839A], 
$P=0.045)$. However, there were no significant differences for the 22 SNPs for the remaining opiate-dependence variables (age at first use, age at regular use, years of regular use, and frequency of use) excluding the six sites mentioned above concerning the frequency of opiate use (Table 3).

The duration since last positive urine screening for opiates was not significantly different according to the different genotypes ( $P>0.3$, data not shown). Opiate drug consumption and the number of drug treatments, detoxification, and rehabilitation were also not significantly different among opiatedependent patients ( $P>0.2$; data not shown). Exploratory comparisons between SNPs' OPRM1 and psychiatric status (eg, impulsiveness, depression, anxiety, craving of euphoria, and diminution of attention) at admission and past history as obtained from their medical records (family with history of drug use, overdose toxicity, and suicide attempts) found no significant group differences in opiate-dependent patients $(P>0.1$, data not shown).

\section{Discussion}

Opiate dependence is a significant public health issue with approximately 10 million people abusing illicit opioids worldwide. ${ }^{51}$ Hulse et al suggested that opiate dependence is not only associated with high mortality rates and poor health among dependent individuals, but also imposes excessively

Table 3 Differences in genotyping distribution of OPRMI SNPs with frequency of opiate use

\begin{tabular}{|c|c|c|}
\hline Variable & SNP_ID & $P$ value \\
\hline \multirow[t]{22}{*}{ Frequency of opiate use (mean: $3.6[0.8]$ ) } & rs69|2029 & 1.000 \\
\hline & rs 12205732 & 1.000 \\
\hline & rsI79997| & 0.827 \\
\hline & rs510769 & 0.338 \\
\hline & rs5II435 & 0.422 \\
\hline & rs52473I & 0.327 \\
\hline & rs3823010 & 0.303 \\
\hline & rs 1381376 & 0.391 \\
\hline & rs3778I5I & 0.292 \\
\hline & rs563649 & 0.165 \\
\hline & rs2075572 & 0.011 \\
\hline & rs540825 & 0.045 \\
\hline & rs675026 & 0.129 \\
\hline & rs562859 & 0.090 \\
\hline & rs548646 & 0.067 \\
\hline & rs648007 & 0.063 \\
\hline & rs9322447 & 0.038 \\
\hline & rs609|48 & 0.028 \\
\hline & rs606I48 & 0.263 \\
\hline & rs632395 & 0.201 \\
\hline & rs648893 & 0.014 \\
\hline & rs67|53I & 0.032 \\
\hline
\end{tabular}

Notes: Fisher's exact test ( $P$ value $<0.05$ is significant).

Abbreviation: SNP, single nucleotide polymorphism. large economic and social costs upon the community in general. ${ }^{3}$ Considerable medical, legal, and interpersonal harm, including mortality, is associated with opiate use. ${ }^{3}$ The major cause of premature death amongst Jordanian opiate users is accidental overdose, along with infectious diseases. ${ }^{52}$ Moreover, a high prevalence of criminal activity and psychosocial difficulties are also found among Jordanian heroin users. ${ }^{52}$

The extent of this serious problem has stimulated considerable interest in the physiological and neurochemical processes involved in opioid dependence. In this respect, there is growing evidence that opiate dependence is influenced by genetic factors. ${ }^{53-55}$ Several studies have been undertaken to estimate the role that genetic factors play in the vulnerability to opiate dependence. ${ }^{19,56-59}$ These studies have shown that the endogenous opioid system in particular is considered to be one of the most important signaling pathways involved in opiate dependence. ${ }^{60}$ This system includes the $\mu$ opioid receptor, which is the primary site of action for the most commonly used opioids including morphine, heroin, and fentanyl and $\mu$-opioid receptor antagonists such as naltrexone, ${ }^{24}$ agonists such as methadone ${ }^{25}$ or partial antagonists such as buprenorphine. ${ }^{20}$ This system may also play a crucial role in mediating the reinforcement effects of nonopioid drugs such as alcohol, cannabinoids, nicotine, and cocaine. ${ }^{60-62}$

In the current study, our aim was to identify the genetic factors associated with responsiveness to the biopsychosocial treatment offered for opiate drug-dependent patients at the NCRA and the DRC-PSD. Drug-dependent patients of Arab descent were genotyped for variance in the OPRM1 gene. The genotyping was carried out by sequenom MassARRAY ${ }^{\circledR}$ system for 22 OPRM1 SNPs. All OPRM1 polymorphisms, which were genotyped in this study, are reported in the NCBI database (http://www.ncbi.nlm.nih.gov/SNP/). This is, to our knowledge, the first attempt to evaluate a series of SNPs spanning the coding sequence of the OPRMI gene in an opiate-using Jordanian Arab population in relation to the response to the biopsychosocial treatment.

Various alcohol or drug dependence-related association studies have expanded their investigation to include up to 20 SNPs spanning the coding sequence of the OPRM1 gene; all include the A118G (Asn40Asp) variants. For instance, Japanese subjects meeting ICD-10 criteria for methamphetamine (MAP) dependence and controls were genotyped for 20 SNPs including 10 SNPs in the 3'-UTR region. ${ }^{63}$ The study reported that A118G and other SNPs were not associated with MAP dependence or psychosis, and the rs2075572 G-allele was significantly associated only with increased risk for a diagnosis of MAP dependence 
Table 4 Association of OPRMI SNPs with treatment outcome

\begin{tabular}{|c|c|c|c|c|}
\hline $\begin{array}{l}\text { SNP_ID/ } \\
\text { genotype }\end{array}$ & $\begin{array}{l}\text { Good } \\
\text { responders }\end{array}$ & $\begin{array}{l}\text { Moderate } \\
\text { responders }\end{array}$ & $\begin{array}{l}\text { Poor } \\
\text { responders }\end{array}$ & $P$ value \\
\hline \multicolumn{5}{|l|}{ rs69|2029 } \\
\hline GG & $34 \%$ & $18 \%$ & $48 \%$ & $0.0329^{a}$ \\
\hline GT & $100 \%$ & $0 \%$ & $0 \%$ & \\
\hline $\mathrm{TT}$ & $0 \%$ & $0 \%$ & $0 \%$ & \\
\hline \multicolumn{5}{|c|}{ rs| 2205732} \\
\hline GG & $35 \%$ & $18 \%$ & $47 \%$ & $0.0333^{\mathrm{a}}$ \\
\hline AG & $100 \%$ & $0 \%$ & $0 \%$ & \\
\hline$A A$ & $0 \%$ & $0 \%$ & $0 \%$ & \\
\hline \multicolumn{5}{|l|}{ rsI79997I } \\
\hline GG & $33 \%$ & $0 \%$ & $67 \%$ & $0.5440^{\mathrm{b}}$ \\
\hline AG & $43 \%$ & $18 \%$ & $39 \%$ & \\
\hline AA & $34 \%$ & $18 \%$ & $48 \%$ & \\
\hline \multicolumn{5}{|l|}{ rs510769 } \\
\hline GG & $36 \%$ & $15 \%$ & $48 \%$ & $0.6040^{\mathrm{b}}$ \\
\hline$A G$ & $37 \%$ & $22 \%$ & $41 \%$ & \\
\hline AA & $17 \%$ & $17 \%$ & $67 \%$ & \\
\hline \multicolumn{5}{|l|}{ rs51I435 } \\
\hline GG & $38 \%$ & $15 \%$ & $47 \%$ & $0.4740^{\mathrm{b}}$ \\
\hline AG & $33 \%$ & $24 \%$ & $43 \%$ & \\
\hline $\mathrm{AA}$ & $17 \%$ & $17 \%$ & $67 \%$ & \\
\hline \multicolumn{5}{|l|}{ rs52473I } \\
\hline $\mathrm{AA}$ & $17 \%$ & $17 \%$ & $67 \%$ & $0.4400^{\mathrm{b}}$ \\
\hline$A C$ & $32 \%$ & $25 \%$ & $43 \%$ & \\
\hline$C C$ & $38 \%$ & $15 \%$ & $47 \%$ & \\
\hline \multicolumn{5}{|l|}{ rs3823010 } \\
\hline GG & $37 \%$ & $16 \%$ & $47 \%$ & $0.8000^{\mathrm{a}}$ \\
\hline AG & $33 \%$ & $23 \%$ & $43 \%$ & \\
\hline $\mathrm{AA}$ & $25 \%$ & $25 \%$ & $50 \%$ & \\
\hline \multicolumn{5}{|l|}{ rs|38|376 } \\
\hline GG & $36 \%$ & $16 \%$ & $48 \%$ & $0.7600^{\mathrm{a}}$ \\
\hline AG & $34 \%$ & $24 \%$ & $41 \%$ & \\
\hline $\mathrm{AA}$ & $25 \%$ & $25 \%$ & $50 \%$ & \\
\hline \multicolumn{5}{|l|}{ rs3778I5I } \\
\hline $\mathrm{CC}$ & $25 \%$ & $25 \%$ & $50 \%$ & $0.8980^{\mathrm{a}}$ \\
\hline $\mathrm{CT}$ & $36 \%$ & $21 \%$ & $42 \%$ & \\
\hline $\mathrm{TT}$ & $36 \%$ & $16 \%$ & $47 \%$ & \\
\hline \multicolumn{5}{|l|}{ rs563649 } \\
\hline GG & $36 \%$ & $17 \%$ & $47 \%$ & $0.9550^{\mathrm{b}}$ \\
\hline AG & $35 \%$ & $19 \%$ & $45 \%$ & \\
\hline $\mathrm{AA}$ & $0 \%$ & $0 \%$ & $0 \%$ & \\
\hline \multicolumn{5}{|l|}{ rs2075572 } \\
\hline GG & $42 \%$ & $8 \%$ & $50 \%$ & $0.5080^{\mathrm{b}}$ \\
\hline GC & $32 \%$ & $20 \%$ & $48 \%$ & \\
\hline CC & $38 \%$ & $19 \%$ & $43 \%$ & \\
\hline \multicolumn{5}{|l|}{ rs540825 } \\
\hline TT & $38 \%$ & $8 \%$ & $54 \%$ & $0.2440^{\mathrm{b}}$ \\
\hline TA & $39 \%$ & $11 \%$ & $50 \%$ & \\
\hline $\mathrm{AA}$ & $33 \%$ & $23 \%$ & $44 \%$ & \\
\hline \multicolumn{5}{|l|}{ rs675026 } \\
\hline CC & $35 \%$ & $21 \%$ & $44 \%$ & $0.6940^{\mathrm{b}}$ \\
\hline $\mathrm{CT}$ & $38 \%$ & $16 \%$ & $46 \%$ & \\
\hline TT & $33 \%$ & $10 \%$ & $57 \%$ & \\
\hline \multicolumn{5}{|l|}{ rs562859 } \\
\hline GG & $35 \%$ & $9 \%$ & $57 \%$ & $0.6690^{\mathrm{b}}$ \\
\hline$A G$ & $37 \%$ & $16 \%$ & $47 \%$ & \\
\hline$A A$ & $35 \%$ & $21 \%$ & $44 \%$ & \\
\hline
\end{tabular}

Table 4 (Continued)

\begin{tabular}{|c|c|c|c|c|}
\hline $\begin{array}{l}\text { SNP_ID/ } \\
\text { genotype }\end{array}$ & $\begin{array}{l}\text { Good } \\
\text { responders }\end{array}$ & $\begin{array}{l}\text { Moderate } \\
\text { responders }\end{array}$ & $\begin{array}{l}\text { Poor } \\
\text { responders }\end{array}$ & $P$ value \\
\hline \multicolumn{5}{|l|}{ rs548646 } \\
\hline $\mathrm{CC}$ & $33 \%$ & $22 \%$ & $46 \%$ & $0.6360^{\mathrm{b}}$ \\
\hline $\mathrm{CT}$ & $38 \%$ & $17 \%$ & $45 \%$ & \\
\hline TT & $35 \%$ & $9 \%$ & $57 \%$ & \\
\hline \multicolumn{5}{|l|}{ rs648007 } \\
\hline $\mathrm{CC}$ & $33 \%$ & $22 \%$ & $46 \%$ & $0.6310^{\mathrm{b}}$ \\
\hline $\mathrm{CT}$ & $38 \%$ & $16 \%$ & $46 \%$ & \\
\hline TT & $35 \%$ & $9 \%$ & $57 \%$ & \\
\hline \multicolumn{5}{|l|}{ rs9322447 } \\
\hline GG & $41 \%$ & $17 \%$ & $41 \%$ & $0.2300^{\mathrm{b}}$ \\
\hline$A G$ & $29 \%$ & $22 \%$ & $49 \%$ & \\
\hline AA & $44 \%$ & $9 \%$ & $47 \%$ & \\
\hline \multicolumn{5}{|l|}{ rs609|48 } \\
\hline $\mathrm{CC}$ & $32 \%$ & $23 \%$ & $45 \%$ & $0.2220^{\mathrm{b}}$ \\
\hline $\mathrm{CT}$ & $41 \%$ & $11 \%$ & $48 \%$ & \\
\hline $\mathrm{TT}$ & $40 \%$ & $7 \%$ & $53 \%$ & \\
\hline \multicolumn{5}{|l|}{ rs606|48 } \\
\hline GG & $36 \%$ & $16 \%$ & $48 \%$ & $0.4040^{\mathrm{a}}$ \\
\hline GT & $38 \%$ & $25 \%$ & $38 \%$ & \\
\hline TT & $0 \%$ & $50 \%$ & $50 \%$ & \\
\hline \multicolumn{5}{|l|}{ rs632395 } \\
\hline CC & $36 \%$ & $16 \%$ & $47 \%$ & $0.6620^{\mathrm{a}}$ \\
\hline $\mathrm{CT}$ & $36 \%$ & $21 \%$ & $43 \%$ & \\
\hline $\mathrm{TT}$ & $0 \%$ & $50 \%$ & $50 \%$ & \\
\hline \multicolumn{5}{|l|}{ rs648893 } \\
\hline $\mathrm{CC}$ & $47 \%$ & $7 \%$ & $47 \%$ & $0.2510^{\mathrm{b}}$ \\
\hline $\mathrm{CT}$ & $39 \%$ & $11 \%$ & $50 \%$ & \\
\hline $\mathrm{TT}$ & $33 \%$ & $23 \%$ & $44 \%$ & \\
\hline \multicolumn{5}{|l|}{ rs67|53I } \\
\hline GG & $34 \%$ & $21 \%$ & $45 \%$ & $0.5770^{\mathrm{b}}$ \\
\hline$A G$ & $36 \%$ & $18 \%$ & $46 \%$ & \\
\hline AA & $39 \%$ & $7 \%$ & $54 \%$ & \\
\hline
\end{tabular}

Notes: aFisher's exact test; 'Pearson's Chi-squared test.

Abbreviation: SNP, single nucleotide polymorphism.

or psychosis $(P=0.011)$. Ten SNPs selected throughout OPRM1 were examined within a Chinese population to investigate the relationship between the SNPs and heroininduced subjective responses. ${ }^{64}$ The study reported that three SNPs in intron 1 were associated with an increased risk of positive responses on first use of heroin and were likely to contribute to further heroin consumption; A118G and rs2075572 were not associated with any differences in heroin-induced subjective responses. In another association study, eight SNPs within OPRM1 in alcohol-1, cocaine-, opioid-, and polysubstance-dependent European Americans (EA) and African Americans (AA) were genotyped. ${ }^{65}$ The EA and AA study reported that C-2044A polymorphism was associated with the combination of alcohol and opioid dependence in EA subjects, but not AA subjects. Again, A118G was not associated with any of the substancedependent phenotypes. A genetic association study on the 
role of OPRM1 genetic variations in a large case-control sample of alcohol- and drug- (cocaine and opioid) dependent European Americans was conducted by Zhang et al. ${ }^{38}$ They typed 13 SNPs representing the major haplotypes observed in HapMap, all of which are included in the present study. They found that seven SNPs (but not rs1799971 [A188G]) were associated with alcohol, opioid, and cocaine dependency. Zhang et $\mathrm{al}^{38}$ found that the frequency of the rs524731 A and rs648893 T alleles was significantly higher among EA than AA subjects. Finally, a case-control study of opiate and nonopiate-dependent Jordanian Arabs was recently conducted by AL-Eitan et $\mathrm{al}^{66}$ to investigate the genetic association of 22 SNPs spanning the coding sequence of the OPRM1 locus with opiate dependence. ${ }^{66}$ The study reported that three SNPs (rs6912029 [G-172T], rs12205732 [G-1510A], and rs563649 [G-983A]) were associated with opiate dependence. ${ }^{66}$ In the present study, these 22 SNPs were also tested for a possible association of OPRM1 polymorphisms with response to the biopsychosocial treatment.

Analysis of the relationship between treatment response and the OPRM1 SNP genotypes showed there was a significant difference in the genotyping distribution between the three inclusion groups at two sites (rs6912029 [G-172T], and rs12205732 [G-1510A]) of the OPRM1 gene located in the upstream $\left(5^{\prime}\right.$-UTR) region. UTRs are known to play crucial roles in the post-transcriptional regulation of gene expression, including modulation of the transport of mRNAs out of the nucleus and of translation efficiency, ${ }^{67}$ subcellular localization, ${ }^{68}$ and stability. ${ }^{69}$ The importance of UTRs in regulating gene expression is underlined by the finding that mutations that alter the UTR can lead to serious pathology.

Previous studies have reported an association of the OPRM1 118A > G with different opioids ${ }^{22,70-73}$ and opiate antagonist "naltrexone" treatment. ${ }^{37,72}$ However, we found no influence of this SNP on responsiveness to treatment, as the allele and genotypes' frequencies were similar in the opiate-dependent patients with a $P>0.05$. A recent study demonstrated that individuals with the Asp40 variants of the OPRM1 gene showed favorably higher relapse prevention rates when receiving naltrexone treatment. ${ }^{42} \mathrm{~A}$ recent clinical trial also showed that the variants of the OPRM1 gene did not have any preferential effect on naltrexone treatment in alcoholics. ${ }^{70}$ The functional importance of treatment on any of the variants of the OPRM1 gene is still being elucidated. Although earlier studies in transfected cells reported that the OPRM1-Asp40 (118G) variant had a threefold higher affinity for $\beta$-endorphin than OPRM1-Asn40 (G118), which would suggest enhanced function, ${ }^{23}$ this was not reported by others. ${ }^{33,34}$ In addition, recent in vitro transfection studies have suggested that the Asp40 allele might be associated with lower OPRM1 protein expression than the Asp40 allele. ${ }^{35}$ As a result, a higher frequency of this allele would have been more common in the individuals with poor treatment response.

Various genetic studies have reported that the frequency of the Asp40 allele can vary significantly between populations with drug dependence from as low as $5 \%$ in African Americans ${ }^{15}$ to $16 \%$ in European Americans ${ }^{38}$ to $26 \%$ in this study of Arab descent ${ }^{66}$ and as high as $58 \%$ among those of Asian descent. ${ }^{39}$ Although the complexity of opiate dependence and the differences in ethnicity have influences on the OPRMI results, all the previous studies have confidence in the hypothesis that the Asp40 allele might be associated with lower OPRM1 protein expression than the Asn 40 allele. ${ }^{35}$ As a result, a higher frequency of the Asp40 allele would have been expected in the poor responder group as compared to the responder group. Similarly, this study found that opiate-dependent patients with poor treatment response had a higher frequency of Asp40 allele and this was in agreement with the proposed theory.

In a search for the relationship between the dependence variables of opiate dependence and the OPRM1 SNPs' genotypes, none of the analyzed SNPs in this study were associated with the age of opiate initiation, transition to opiate dependence, and regular use and opiate consumption (beginning and last taken amount [grams per day]). However, the data indicated that there were significant differences in opiate frequency use at only six sites (rs2075572 [C644-83G], rs648893 [C1165-1189T], rs609148 [G1165-8803T], rs671531 [A1164+28135A G], rs9322447 [G1164+11714A], rs540825 [T1164+1839A]) of the OPRM1 gene with $P<0.05$. Previous studies have indicated that $O P R M 1$ polymorphism may be associated with clinical variables such as treatment duration, hospitalization for drug treatments, detoxification, rehabilitation, counseling and self-help for substance abuse, psychiatric symptoms, history of drug use, overdose toxicity, and follow-up measures (urine screening test). ${ }^{15,39,45,46,62,71}$ Unfortunately, the $P$ values concerning the clinical variables in this study were not significant.

This discrepancy between the study results could be related to the past history, the psychiatric status, and the subgroups of drug-dependent individuals with violent behavior. This might be due to a bias in classifying the drug-dependent individuals. There are some possible confounding factors that should be taken into consideration when assessing the patients with drug dependence such as the methods used for defining violent, antisocial behavior and the early onset 
of dependence. Several studies have based patients' assessment on collecting the phenotypic data by only a self-report, interviewing the patients by health professional workers, or obtaining the data from their medical records, including this study.

Previous studies have shown that some OPRM1 markers deviate from the Hardy-Weinberg Equilibrium (HWE) in different populations. ${ }^{38,74}$ There are many possible confounding factors for this deviation including population stratification, genotyping errors, and true association with phenotypes. ${ }^{74}$ In this study, the genotypic frequencies of the OPRM1 markers met HWE expectations. Other studies have also reported sample bias or genotyping errors. Our patients were from one geographic origin and were 100\% native Jordanians of Arab ancestry, which is a population known to be genetically homogenous. Genotyping errors were minimized by genotyping each patient twice in order to avoid technical errors as evidenced by the low average rate of genotype discrepancy. SNPs' genotyping was conducted for patients under the same conditions and during the same period. Genotypes were also evaluated by investigators, who were blind to the status of the subject and any discrepancies were resolved by test replication. Finally, only male individuals with opiate dependence were studied. Therefore, the generalization of the results to all drug-dependent patients is limited.

In conclusion, this is the first report of an association between the OPRM1 G-172T and G-1510A polymorphisms and response to the biopsychosocial treatment. Specifically, the GG-172 and GG-1510 carriers were more frequent in nonresponders to treatment. This may lead to more accurate matching of individuals to different treatment options and early identification of persons at high risk of relapse and therefore requiring more intensive intervention. However, further pharmacogenetic studies are needed to confirm the present findings on the influence of the OPRM1 G-172T and G-1510A on the response to treatment in opiate-dependent patients of Arab descent.

\section{Acknowledgments}

Publication number LA011-007 of the Centre for Forensic Science at the University of Western Australia. We gratefully acknowledge the contribution of participating patients whose cooperation made this study possible. Funding for this project was provided in part by Centre for Forensic Science and Unit for Research and Education in Alcohol and Drugs of the School of Psychiatry and Clinical Neurosciences, The University of Western Australia.

\section{Disclosure}

The authors report no conflicts of interest in this work.

\section{References}

1. Tsuang MT, Lyons MJ, Meyer JM, et al. Co-occurrence of abuse of different drugs in men: the role of drugs-specific and shared vulnerabilities. Arch Gen Psychiatry. 1998;55:967-972.

2. Anthony JC, Warner LA, Kessler RC. Comparative epidemiology of dependence on tobacco, alcohol, controlled substances, and inhalants: basic findings from the national comorbidity survey. Exp Clin Psychopharmacol. 1994;2:244-268.

3. Hulse GK, English DR, Milne E. The quantification of mortality resulting from the regular use of illicit opiates. Addiction. 1999;94: 221-229.

4. Nutt D, King LA, Saulsbury W, Blakemore C. Development of a rational scale to assess the harm of drugs of potential misuse. Lancet. 2007;369: 1047-1063.

5. Bament D, Cooke R, Weekley J, Ali R. Treatment outcomes at 12 months post admission to drug treatment: The third report of the South Australian component of the Australian Treatment Outcomes Study - Heroin. Adelaide: DASC Monograph No 16 Research Series. 2004.

6. Ball J, Ross A. The Effectiveness of Methadone Maintenance Treatment. New York, NY: Springer-Verlag; 1991.

7. Johnson BA, editor. Addiction Medicine: Science and Practice. New York, NY: Springer; 2011.

8. Eap CB, Buclin T, Baumann P. Interindividual variability of the clinical pharmacokinetics of methadone: implications for the treatment of opioid dependence. Clin Pharmacokinet. 2002;41:1153-1193.

9. Crettol S, Déglon JJ, Besson J, et al. ABCB1 and cytochrome P450 genotypes and phenotypes: influence on methadone plasma levels and response to treatment. Clin Pharmacol Ther. 2006;80:668-681.

10. Srisurapanont M, Jarusuraisin N. Naltrexone for the treatment of alcoholism: a meta-analysis of randomized controlled trials. Int $J$ Neuropsychopharmacol. 2005;8(2):267-280.

11. Streeton C, Whelan G. Naltrexone, a relapse prevention maintenance treatment of alcohol dependence: a meta-analysis of randomized controlled trials. Alcohol. 2001;36(6):544-552.

12. Kranzler HR, Van Kirk J. Efficacy of naltrexone and acamprosate for alcoholism treatment: a meta-analysis. Alcohol Clin Exp Res. 2001; 25(9):1335-1341.

13. Bouza C, Angeles M, Munoz A, Amate J. Efficacy and safety of naltrexone and acamprosate in the treatment of alcohol dependence: a systematic review. Addiction. 2004;99(7):811-828.

14. Anton RF, O'Malley SS, Ciraulo DA, et al. COMBINE Study Research Group. Combined pharmacotherapies and behavioral interventions for alcohol dependence: the COMBINE study: a randomized controlled trial. JAMA. 2006;295(17):2003-2017.

15. Gelernter J, Kranzler H, Cubells J. Genetics of two mu opioid receptor gene (OPRMI) exon I polymorphisms: population studies, and allele frequencies in alcohol- and drug-dependent subjects. Mol Psychiatry. 1999;4:476-483.

16. Anton RF, Oroszi G, O’Malley S, et al. An evaluation of mu opioid receptor $(O P R M 1)$ as a predictor of naltrexone response in the treatment of alcohol dependence: results from the combined pharmacotherapies and behavioral interventions for alcohol dependence (COMBINE) study. Arch Gen Psychiatry. 2008;65(2):135-144.

17. Kim SG, Kim CM, Kang DH, et al. Association of functional opioid receptor genotypes with alcohol dependence in Koreans. Alcohol Clin Exp Res. 2004;28:986-990.

18. Gianoulakis C, Krishnan B, Thavundayil J. Enhanced sensitivity of pituitary $\beta$-endorphin to ethanol in subjects at high risk of alcoholism. Arch Gen Psychiatry. 1996;53(3):250-257.

19. Haile CN, Kosten TA, Kosten TR. Pharmacogenetic treatments for drug addiction: alcohol and opiates. Am J Drug Alcohol Abuse. 2008;34(4): 355-381. 
20. Kreek MJ, Vocci FJ. History and current status of opioid maintenance treatments: blending conference session. J Subst Abuse Treat. 2002; 23(2):93-105.

21. Kreek MJ, Bart G, Lilly C, et al. Pharmacogenetics and human molecular genetics of opiate and cocaine addictions and their treatments, Pharmacol. 2005;57(1):1-26.

22. Ravindranathan A, Joslyn G, Robertson M, et al. Functional characterization of human variants of the mu opioid receptor gene. Proc Natl Acad Sci U S A. 2009;106(26):10811-10816.

23. Beyer A, Koch T, Schröder H, Schulz S, Hollt V. Effect of the A118G polymorphism on binding affinity, potency and agonist-mediated endocytosis, desensitization, and resensitization of the human mu opioid receptor. J Neurochem. 2004;89:553-560.

24. Volpicelli JR, Alterman AI, Hayashida M, O'Brien CP. Naltrexone in the treatment of alcohol dependence. Arch Gen Psychiatry. 1992; 49(11):876-880.

25. Dole VP, Nyswander M. A medical treatment for diacetylmorphine (heroin) addiction. A clinical trial with methadone hydrochloride. JAMA. 1965;193:646-650.

26. Benyhe $\mathrm{S}$, Tóth $\mathrm{G}$, Kevei J, et al. Characterization of rat brain opioid receptors by (Tyr-3, 5-3H)1,D-Ala2,Leu5-enkephalin binding. Neurochem Res. 1985;10:627-635.

27. Chen Y, Mestek A, Liu J, Hurley JA, Yu L. Molecular cloning and functional expression of a $\mu$-opioid receptor from rat brain. Mol Pharmacol. 1993;44:8-12.

28. Delfs CL, Kong H, Mestek A, et al. Expression of mu opioid receptor mRNA in rat brain: an in situ hybridization study at single cell level. J Comp Neurol. 1994;345:46-68.

29. Waldhoer M, Bartlett SE, Whistler JL. Opioid receptors. Annu Rev Biochem. 2004;73:953-990.

30. Hoehe MR, Kopke K, Wendel B, et al. Sequence variability and candidate gene analysis in complex disease: association of mu opioid receptor gene variation with substance dependence. Hum Mol Gene. 2000;9:2895-2908.

31. Ikeda MR, Ide S, Han W, et al. How individual sensitivity to opiates can be predicted by gene analyses. Trend Pharmacol Sci. 2005;26: 311-317.

32. Bergen AW, Koskozka J, Peterson R, et al. Mu opioid receptor gene variants: lack of association with alcohol dependence. Mol Psychiatry. 1997;2:490-497.

33. Bond C, Laforge KS, Tian M, et al. Single nucleotide polymorphism in the human mu opioid receptor gene alters beta-endorphin binding and activity: possible implications for opiate addiction. Proc Natl Acad Sci US A. 1998;95(16):9608-9613.

34. Befort K, Filliol D, Décaillot FM, et al. Single nucleotide polymorphic mutation in the human mu opioid receptor severely impairs receptor signalling. J Biol Chem. 2001;276:3130-3137.

35. Zhang Y, Wang D, Johnson AD, Papp AC, Sadee W. Allelic expression imbalance of human mu opioid receptor (OPRM1) caused by variant A118G. J Biol Chem. 2005;280(38):32618-32624.

36. Arias A, Feinn R, Kranzler HR. Association of an Asn40Asp (A118G) polymorphism in the mu opioid receptor gene with substance dependence: a meta-analysis. Drug and Alcohol Depend. 2006;83:262-268.

37. Oroszi G, Anton RF, O'Malley S, et al. OPRM1 Asn40Asp predicts response to naltrexone treatment: A haplotype based approach. Exp Clin Psychopharmacol. 2009;33(3):383-393.

38. Zhang H, Luo X, Kranzler HR, et al. Association between two mu opioid receptor gene $(O P R M 1)$ haplotype blocks and drug or alcohol dependence. Hum Mol Genet. 2006;15:807-819.

39. Kim SG, Kim CM, Choi SW, et al. A mu opioid receptor gene polymorphism (A118G) and naltrexone treatment response in adherent Korean alcohol-dependent patients. Psychopharmacology. 2009; 201:611-618.

40. Karhuvaara S, Simojoki K, Virta A, et al. Targeted nalmefene with simple medical management in the treatment of heavy drinkers: a randomized double-blind placebo-controlled multicentre study. Alcohol Clin Exp Res. 2007;31:1179-1187.
41. Krystal JH, Cramer JA, Krol WF, Kirk GF, Rosenheck RA. Naltrexone in the treatment of alcohol dependence. $N$ Engl J Med. 2001;345: 1734-1739.

42. Oslin DW, Berrettini W, Kranzler HR, et al. A functional polymorphism of the mu opioid receptor gene is associated with naltrexone response in alcohol-dependent patients. Neuropsychopharmacology. 2003;28:1546-1552.

43. American Psychiatric Association. Diagnostic and Statistical Manual of Mental Disorders. 4th ed. Washington, D.C.: American Psychiatric Association; 1994.

44. McLellan AT, Cacciola J, Kushner H. The fifth edition of the addiction severity index: Cautions, additions and normative data. J Subst Abuse Treat. 1992;9:461-480.

45. McGue M, Pickens RW, Svikis DS. Sex and age effects on the inheritance of alcohol problems: a twin study. J Abnorm Psychol. 1992; 101:3-17.

46. Berrettini WH, Persico AM. Dopamine D2 receptor gene polymorphisms and vulnerability to substance abuse in African-Americans. Biol Psychiatry. 1996;40:144-147.

47. Bare LA, Mansson E, Yang D. Expression of two variants of the human mu opioid receptor mRNA in SK-N-SH cells and human brain. FEBS Lett. 1994;354(2):213-216.

48. Xin L, Wang ZJ. Bioinformatics analysis of the human $\mu$ opioid receptor (OPRMI) splice and polymorphic variants. AAPS Pharm Sci. 2002;4:1-13.

49. Pasternak GW. Multiple opiate receptors: déjà vu all over again. Neuropharmacology. 2004;1:312-323.

50. Liu K, Muse SV. PowerMarker: integrated analysis environment for genetic marker data. Bioinformatics. 2005;21:2128-2129.

51. United Nations Office on Drug and Crime (UNODC), country profile, The Hashemite Kingdom of Jordan, 2010. Vienna, Austria. Available from: http://www.unodc.org/egypt/en/country_profile_jordan.html. Accessed December 11, 2011.

52. Hadidi MS, Ibrahim MI, Abdallat IM. Current trends in drug abuse-associated fatalities - Jordan, 2000-2004. Forensic Sci Int. 2009; 186:44-47.

53. Di Chiara G, Imperato A. Drugs abused by humans preferentially increase synaptic dopamine concentrations in the mesolimbic system of freely moving rats. Proc Natl Acad Sci U S A. 1998;85: 5274-5278.

54. Tanda G, Pontieri FE, Di Chiara G. Cannabinoid and heroin activation of mesolimbic dopamine transmission by a common $\mathrm{m} 1$ opioid receptor mechanism. Science. 1997;276:2048-2050.

55. Weiss F, Lorang MT, Bloom FE, Koob GF. Oral alcohol self-administration stimulates dopamine release in the rat nucleus accumbens. Genetic and motivational determinants. J Pharmacol Exp Ther. 1993;267:250-258.

56. Nestler EJ. Genes and addiction. Nat Genet. 2000;26:227-281.

57. Nestler EJ. Molecular neurobiology of addiction. Am J Addict. 2001;10:201-217.

58. Nestler EJ. Opportunities for understanding addiction. J Neurosci. 2001;21:8324-8327.

59. Nestler EJ. Is there a common molecular pathway for addiction? Nat Neurosci. 2005;8:1445-1449.

60. Herz A. Endogenous opioid systems and alcohol addiction. Psychopharmacology. 1997;129:99-111.

61. Laforge KS, Shick V, Spangler R, et al. Detection of single nucleotide polymorphisms of the human mu opioid receptor gene by hybridization or single nucleotide extension on custom oligonucleotide gelpad microchips: potential in studies of addiction. Am J Med Genet. 2000;96:604-615.

62. Ehlers CL, Lind PA, Wilhelmsen KC. Association between single nucleotide polymorphisms in the mu opioid receptor gene (OPRM1) and self-reported responses to alcohol in American Indians. Bio Med Central Medical Genetics. 2008;9:35

63. Ide S, Kobayashi H, Tanaka K, et al. Gene polymorphisms of the mu opioid receptor in methamphetamine abusers. Ann NY Acad Sci. 2004;1025:316-324. 
64. Zhang D, Shao C, Shao M, et al. Effect of mu opioid receptor gene polymorphisms on heroin-induced subjective responses in a Chinese population. Biol Psychiatry. 2007;61:1244-1251.

65. Luo X, Kranzler HR, Zhao H, Gelernter J. Haplotypes at the OPRMI locus are associated with susceptibility to substance dependence in European-Americans. Am J Med Genet B Neuropsychiatr Genet. 2003;120(1):97-108.

66. AL-Eitan LN, Jaradat A, Dadour R, Tay GK, Hulse GK. Polymorphisms in the $\mu$-opioid receptor gene in Jordanian Arabs with opiate drug dependence. Science MED. 2012;3:91-97.

67. Van der Velden AW, Thomas AA. The role of the $5^{\prime}$ untranslated region of an mRNA in translation regulation during development. Int J Biochem Cell Biol. 1999;31:87-106.

68. Jansen RP. mRNA localization: message on the move. Nat Rev Mol Cell Biol. 2001;2:247-256.

69. Bashirullah A, Cooperstock RL, Lipshitz HD. Spatial and temporal control of RNA stability. Proc Natl Acad Sci U S A. 2001;98: 7025-7028.
70. Lötsch J, Zimmermann M, Darimont J, et al. Does the A118G polymorphism at the mu opioid receptor gene protect against morphine6-glucuronide toxicity? Anesthesiology. 2002;97:814-819.

71. Oertel BG, Schmidt R, Schneider A, Geisslinger G, Lotsch J. The $\mathrm{mu}$ opioid receptor gene polymorphism 118A $>\mathrm{G}$ depletes alfentanil-induced analgesia and protects against respiratory depression in homozygous carriers. Pharmacogenet Genomics. 2006;16: 625-636.

72. Romberg RR, Olofsen E, Bijl H. Polymorphism of mu opioid receptor gene (OPRMI:c.118A $>\mathrm{G}$ ) does not protect against opioidinduced respiratory depression despite reduced analgesic response. Anesthesiology. 2005;102:522-530.

73. Crettol S, Besson J, Croquette-Krokar M, et al. Association of dopamine and opioid receptor genetic polymorphisms with response to methadone maintenance treatment. Prog Neuropsychopharmacol Biol Psychiatry. 2008;32:1722-1727.

74. Guo SW, Thompson EA. Performing the exact test of Hardy-Weinberg proportion for multiple alleles. Biometrics. 1992;48:361-337.
Pharmacogenomics and Personalized Medicine

\section{Publish your work in this journal}

Pharmacogenomics and Personalized Medicine is an international, peerreviewed, open access journal characterizing the influence of genotype on pharmacology leading to the development of personalized treatment programs and individualized drug selection for improved safety, efficacy and sustainability. This journal is indexed on the American Chemical

\section{Dovepress}

Society's Chemical Abstracts Service (CAS). The manuscript management system is completely online and includes a very quick and fair peer-review system, which is all easy to use. Visit http://www.dovepress. $\mathrm{com} /$ testimonials.php to read real quotes from published authors.

Submit your manuscript here: http://www.dovepress.com/pharmacogenomics-and-personalized-medicine-journal 